\title{
Cerámica de Tradición Aborigen: legado material indígena en La Habana colonial
}

\author{
Aboriginal Tradition Ceramics: Indigenous \\ Material Legacy in Colonial Havana
}

\author{
Roger Arrazcaeta Delgado \\ ORCID iD: https://orcid.org/0000-0002-3272-6039
}

Gabinete de Arqueología, Oficina del Historiador de La Habana, Cuba

Lisette Roura Álvarez

ORCID iD: https://orcid.org/0000-0003-0323-9116

Gabinete de Arqueología, Oficina del Historiador de La Habana/ Universidad de La Habana, Cuba

\section{Rebeca T. Ortiz Linsuaín}

ORCID iD: https://orcid.org/0000-0003-0869-0352

Gabinete de Arqueología, Oficina del Historiador de La Habana, Cuba

La cerámica analizada en este artículo se reconoce como resultado de la interacción indohispánica en la región habanera. Se enfatizan las características y significación de estos artefactos, en los que se evidencian rasgos identitarios autóctonos, así como la supervivencia de individuos reconocidos socialmente como indios naturales, hacedores de los ceramios referidos. Se profundiza en los procesos sociohistóricos por los que transitaron los miembros de este grupo social, que condicionaron la continuidad de la producción cerámica de tradición aborigen en La Habana.

Palabras Clave: Cuba; Cerámica; Indios; Grupo social; Tradición aborigen.

The ceramics analyzed in this article are recognized as a result of Indo-Hispanic interaction in the Havana region. The study emphasizes the characteristics and significance of these artifacts, in which signs of autochthonous identity are observed, as well as the survival of individuals socially recognized as native Indians, makers of the aforementioned ceramics. Furthermore, we inquire into the sociohistorical processes through which the members of this social group passed, which conditioned the continuity of ceramic production of the aboriginal tradition in Havana.

KeYwords: Cuba; Ceramics; Indians; Social Group; Aboriginal Tradition.

Copyright: (C) 2020 CSIC. Este es un artículo de acceso abierto distribuido bajo los términos de la licencia de uso y distribución Creative Commons Reconocimiento 4.0 Internacional (CC BY 4.0). 


\section{Introducción}

La Habana, ${ }^{1}$ a lo largo de su desarrollo, ha tenido la particularidad de constituir un escenario de interacciones culturales significativas, donde la actividad portuaria propició el auge de las operaciones comerciales y la cantidad de estantes ${ }^{2}$ triplicó el número de vecinos y residentes (Figuras 1 y 2). A partir del año 1561, la ciudad se convertiría en el centro del comercio caribeño, ya que los galeones provenientes de Perú y la flota procedente de México se daban cita en el puerto habanero, combinando fuerzas y acopiando las provisiones necesarias para su retorno a España a través del Atlántico. ${ }^{3}$ Esto implicó la constante inmigración de individuos procedentes de diversas regiones, lo que propició la incorporación de variados componentes culturales que fueron asimilados por los pobladores de La Habana en su vida cotidiana, por ejemplo, comidas, vestimentas y elementos vinculados con el lenguaje. Sin embargo, a pesar de las influencias externas, los indios ${ }^{4}$ naturales que habitaban en el territorio habanero parecen haberse incorporado a la sociedad colonial manteniendo rasgos identitarios que han sido identificados en los artefactos cerámicos recuperados de las excavaciones arqueológicas.

Los estudios históricos y arqueológicos vinculados con los indios naturales en La Habana son escasos, a pesar de la importancia que reviste el tema para la historia local, regional y nacional. El análisis de las referencias históricas y arqueológicas evidenció la necesidad de reajustar las estrategias de investigación y superar el manejo aislado de evidencias llamadas «de transculturación», y además reconocer la importancia del conjunto artefactual, así como de las asociaciones significativas contrastables desde los documentos. La revisión crítica de dichos referentes advierte una ausencia de análisis integrador, predominio de estudios de casos, insuficiencia de investigaciones que constaten la continuidad de la tradición ceramista autóctona hasta el siglo XVIII, y de análisis referidos a los procesos

1 Actual provincia de La Habana. Se referirá, en adelante, a los contextos arqueológicos del municipio La Habana Vieja y a los del municipio Guanabacoa, otrora pueblo de indios fundado en el año 1554.

2 Término que designaba a las personas que no constituían vecinos ni residentes, habitaban temporalmente en la ciudad a la espera de las flotas o por motivos diversos.

3 En el año 1561 se establece el sistema de flotas y galeones, mediante el cual se daba protección a las naves y sus cargamentos a través del Atlántico. Este sistema se mantuvo activo hasta 1776, antecediendo el Reglamento de libre Comercio con América, promulgado por el rey Carlos III en 1778.

4 Para ahondar y justificar la utilización de este término, consultar Valcárcel Rojas, 2016, 7-47. 
FIGURA 1

PLANO DE SAN CRISTÓBAL DE LA HABANA, EN PERSPECTIVA (1567)

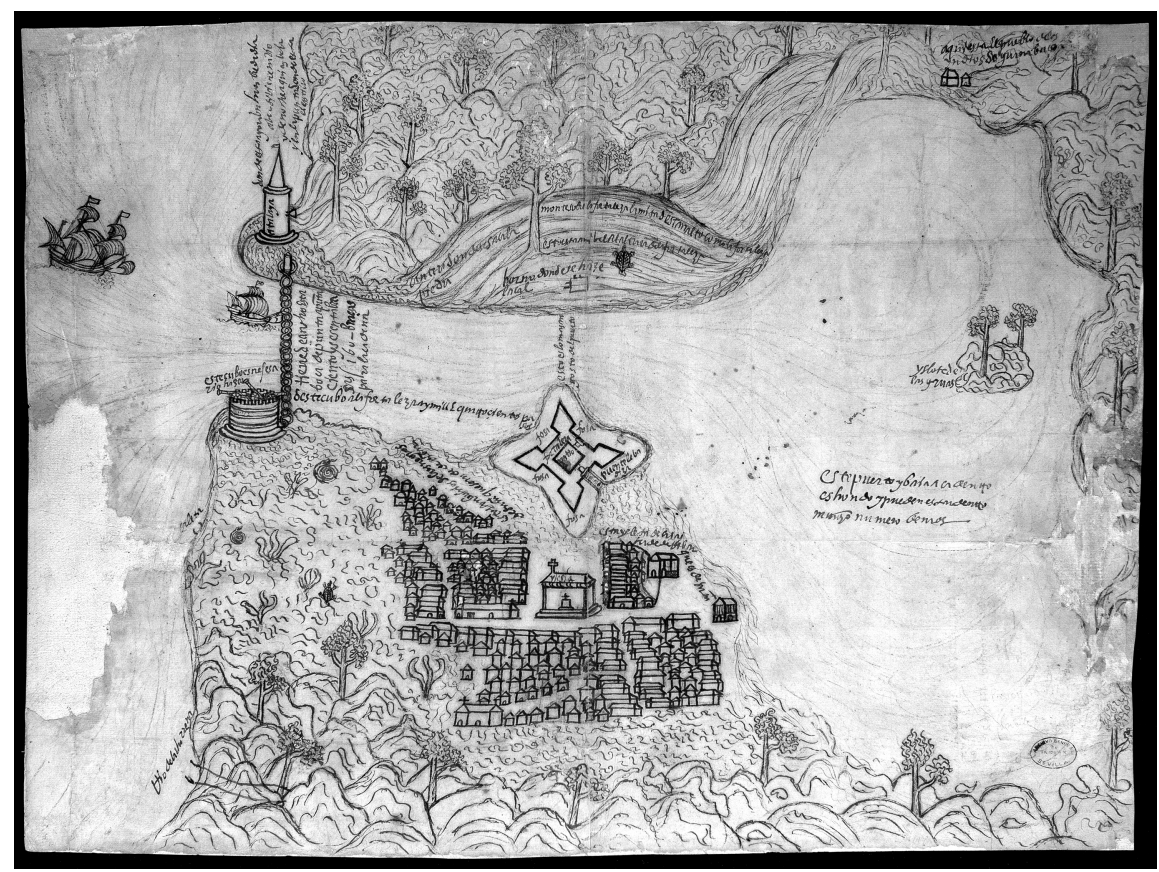

En el extremo superior derecho puede leerse la inscripción «Aqui esta el pueblo de los yndios de guanabacoa» $[\mathrm{sic}]$.

Fuente: España, Ministerio de Cultura y Deporte, Archivo General de Indias, Mapas y Planos, Santo Domingo, 4.

sociohistóricos acaecidos. Igualmente, la necesidad de redefinir la llamada Cerámica Transcultural o Cerámica del Período de Contacto y Transculturación, ya que el conjunto estudiado solamente presenta características identificadas en las cerámicas producidas por las comunidades precolombinas agroalfareras, aun cuando la pérdida de atributos distintivos (decoraciones, espesor y formas) se reconoce como consecuencia del tránsito de estos individuos por el proceso transcultural. Esta situación ha creado un vacío de información que ha legitimado la invisibilidad del indio en la historiografía, 
lo cual ha propiciado que se asuma la desaparición de los naturales durante el siglo XVI; las características formales observadas en las cerámicas arqueológicas confirman la necesidad de repensar la manera en que se ha tratado la temprana desaparición de estos. Se propone entonces la reformulación de aspectos relacionados con la continuidad histórica mediante la retipificación de la comúnmente llamada Cerámica de Transculturación, la persistencia de rasgos identitarios autóctonos y el tránsito de los naturales por procesos sociohistóricos regionales.

\section{FIGURA 2}

UBICACIÓN DE LOS CENTROS URBANOS DE LA HABANA VIEJA Y GUANABACOA, PARTES INTEGRANTES DE LA PROVINCIA LA HABANA

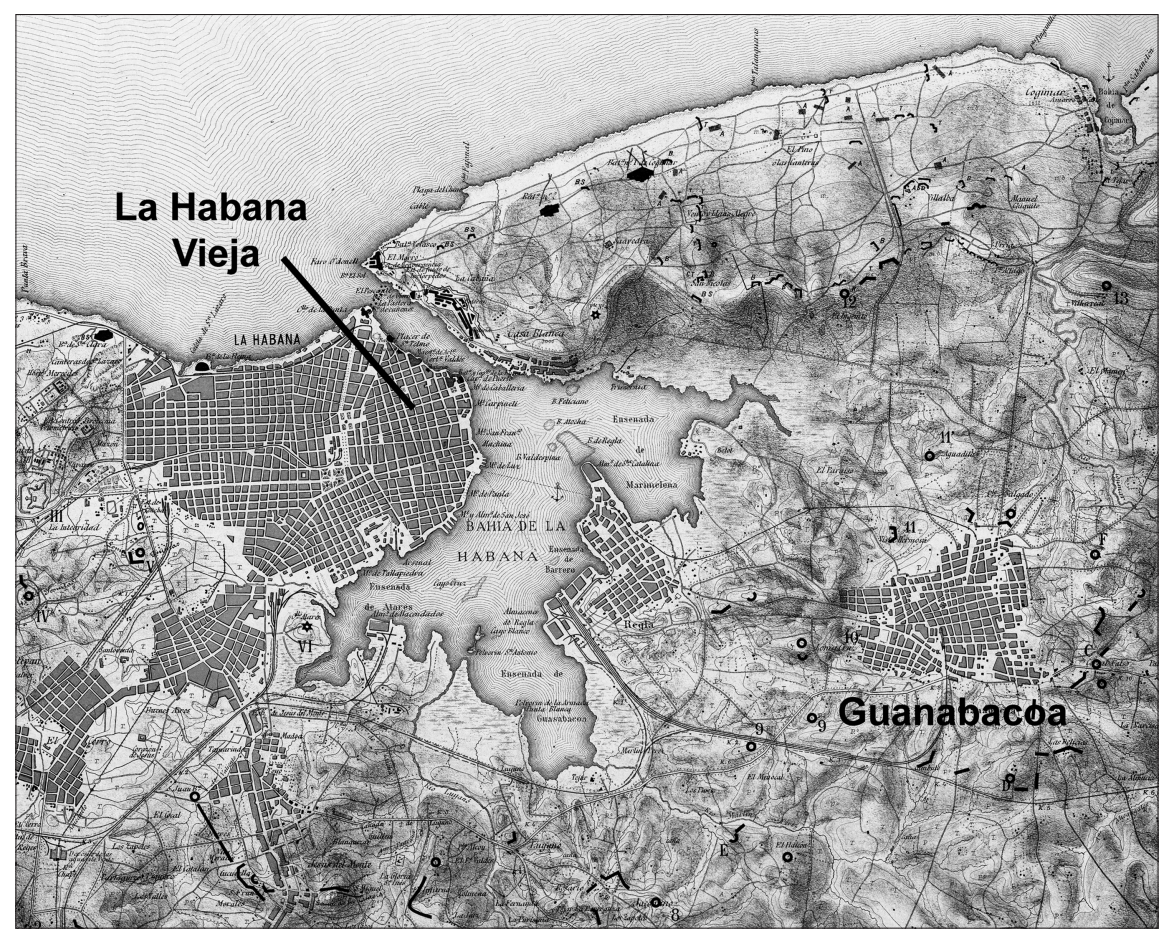

Fuente: Infografía de Lisette Roura Álvarez, sobre fragmento de Severo Gómez Núñez, «Plano de la Plaza de La Habana y de su campo atrincherado», Cuba, 1900-1909. University of Florida Digital Collections. Disponible en: http://ufdc.ufl.edu/AA00063708/00001 [Consultado: 27/08/2020]. 


\section{Apuntes necesarios}

El tipo Cerámica de Tradición Aborigen ${ }^{5}$ pertenece al grupo de la Cerámica Ordinaria, término que se atribuye a la alfarería con una pasta relativamente suave, cocida a una temperatura menor a los $1100^{\circ}$ Celsius. Puede usualmente rayarse con la uña - valor 2 o 3 en la escala de dureza de Mohs - y posee una porosidad elevada. Estos ceramios (Figura 3) presentan variedad en los tamaños y formas básicas (ollas, ${ }^{6}$ cuencos, ${ }^{7}$ potes ${ }^{8}$ y burenes ${ }^{9}$ ); sus atributos formales y las abundantes adherencias de tizne y carbón, sugieren su uso fundamental en actividades culinarias. La fractura es irregular, llamada erizada, típica de cerámica que se cuece a bajas temperaturas. En La Habana, la Cerámica de Tradición Aborigen aparece asociada con artículos de importación europeos, asiáticos y americanos de los siglos XVI, XVII y XVIII. A juzgar por los más de diez mil fragmentos hallados, constituyó un artículo producido masivamente para la venta, a consumir por la emergente sociedad colonial habanera a partir del establecimiento de la villa en su bahía desde 1519.

Fue previamente clasificada como Cerámica Transcultural ${ }^{10}$ o $\mathrm{Ce}$ rámica del Período de Contacto y Transculturación, ${ }^{11}$ tras su reiterada presencia en la Casa de la Obrapía, La Habana Vieja, ${ }^{12}$ y en sitios con evidencias hispanas e indígenas del siglo XVI en la provincia Holguín, hacia el oriente de Cuba. Estos últimos apelativos se debieron a su técnica de hechura, ya que, con excepción de los burenes, fue confeccionada mediante el método de acordelado —enrollado, enrolletado, coiling_-, sobre la base de rollos cilíndricos de arcilla superpuestos y unidos hasta lograr el aspecto deseado.

5 Definido por Roura, Arrazcaeta y Hernández, 2006, 16-27.

6 Vasija cilíndrica de barro, ancha en la barriga, base convexa y más estrecha que la boca; puede portar asas. Tiene una altura «[...] desde ligeramente menor que el diámetro de la boca, hasta ser igual al radio de la boca». Guarch, 1978, 95.

7 Vaso cilíndrico de barro, hondo y ancho, base convexa y más estrecha que la boca «[...] tiene una altura desde ligeramente menor que el radio de la boca hasta la mitad del mismo». Guarch, $1978,95$.

8 Vaso cilíndrico de barro, alto, base convexa y más estrecha que la boca. Tiene una altura «[...] mayor que el diámetro de la boca hasta igual al mismo». Guarch, 1978, 95. alimentos.

9 Tortas discoidales de cerámica cocida, utilizadas para cocer el pan de casabe y otros

10 Domínguez, 1980, 15-26.

11 Romero, 1981, 71-105.

12 Domínguez, 1980. 
FIGURA 3

OLLA (A), CUENCO (B), POTE (C) Y FRAGMENTO DE BURÉN (D) EXHUMADOS EN EL CONVENTO SAN FRANCISCO DE ASÍS, LA HABANA VIEJA

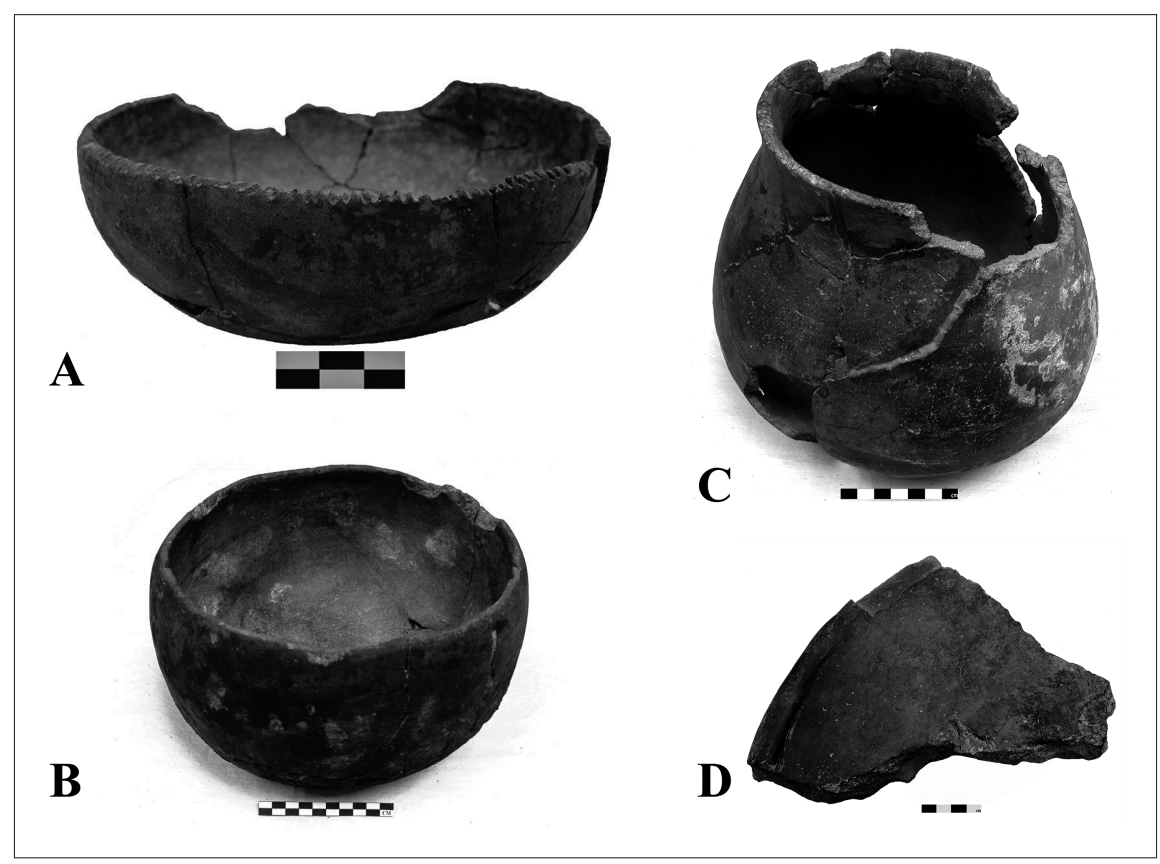

Fuente: Fotografías de Lisette Roura Álvarez.

Esta alfarería aparece en todo tipo de sitio arqueológico, desde fortificaciones, muladares urbanos, conventos, casas familiares de baja solvencia económica y viviendas de clases pudientes. Su producción y popularidad, como demuestra el registro arqueológico, pudo deberse a la escasez de recipientes de cerámica de importación para la cocina, insuficientemente suplidos por el comercio español. También debió jugar un rol substancial la existencia de un mercado local que ofertaba el producto con menor precio, y la idoneidad que tenía en los menesteres de la cocina, posiblemente reputado por su superioridad para preparar comidas específicas respecto a otros recipientes. La existencia de población india en La Habana dedicada, entre otras actividades económicas, a la elaboración de este tipo de cerámica para la subsistencia, debió permitir una estabilidad en la oferta del mercado. 
El constante uso de esta alfarería en actividades diarias y las frecuentes roturas que presentaba como resultado de la baja temperatura de cocción en su fabricación, implicó una continua demanda de ejemplares nuevos para el uso en las labores culinarias.

\section{Mirando hacia el pasado: sitios de contacto y transculturación}

En Cuba, la doctora Lourdes S. Domínguez, a partir de un gran cúmulo de información sedimentada durante años y una visión renovada, propuso una clasificación operativa para diferenciar los sitios de contacto y de transculturación indohispana, con base en el tipo de evidencia hallada. ${ }^{13}$ Para esta investigadora, el contacto implicaba la presencia de materiales europeos y aborígenes, donde los primeros no son abundantes y aparecen solo en los estratos superiores, además de no haber sido modificados: «[...] estos pueden ser producto de la estancia efímera o del paso del colonizador, ocasionalmente, o, en su efecto, traídos por el propio indígena». ${ }^{14}$ No obstante, la referida modificación de los artefactos pudo producirse bilateralmente: por los indígenas o por los españoles. Para Domínguez, un sitio de transculturación tiene características divergentes respecto a uno de contacto, pues presenta cuantiosos materiales europeos mezclados con los típicamente aborígenes en distintas unidades estratigráficas. Algunos de los restos europeos están transformados y reutilizados «[...] o, también, los que son un producto nuevo de la creación de ambos grupos y que son verdaderas piezas transculturales» (Figura 4). Esa situación implicaba una interacción cultural intensa y prolongada en el tiempo.

Las tesis expuestas por la doctora Domínguez conllevaron años de trabajo y de descubrimientos arqueológicos, lo cual debe analizarse desde una perspectiva histórica. En tal sentido, corresponde decir que el primer reporte de un sitio con restos de artefactos europeos y aborígenes data de 1938, cuando el investigador José García Castañeda halló en El Yayal, provincia Holguín, cuantiosos objetos de cerámica, metales ferrosos y no ferrosos, y una «variedad de ollas, platos, tazas y jarros de barro»:15 algunas de las referidas vasijas imitaban formas europeas. Posteriores revisiones del

\footnotetext{
13 Domínguez, 1978, 37.

14 Idem.

15 García, 1938, 45-58.
} 
material cerámico ${ }^{16}$ confirmaron que se inspiraban en formas españolas del siglo XVI, elaboradas con tecnología aborigen. García Castañeda agrupó los artefactos con características indohispanas y europeas en dos categorías: «Objetos de los colonizadores, e Influencia de los colonizadores», ${ }^{17}$ lo cual patentizó la importancia de estos elementos en el sitio.

Durante las décadas de 1930 y 1940 se localizaron y trabajaron más de una docena de sitios clasificados como de contacto y transculturación indohispana en la provincia Holguín, ${ }^{18}$ entre ellos cabe mencionar por su importancia El Yayal, El Porvenir, El Pesquero, El Chorro de Maíta, Potrero del Mango, La Güira de Barajagua, Alcalá y El Catuco. Estos contenían materiales europeos modificados por los indígenas para usarlos como adornos o herramientas, y ceramios que copiaban las formas de recipientes hispanos. El sitio mejor estudiado entre los citados es El Chorro de Maíta, donde el doctor José M. Guarch y su equipo del Departamento Centro Oriental de Arqueología del Ministerio de Ciencias, Tecnología y Medio Ambiente (CITMA), ubicado en la ciudad de Holguín, realizó excavaciones entre los años 1979 y 1988. Durante las investigaciones se excavó un cementerio con más de cien enterramientos, y se realizaron varios estudios de los materiales y restos humanos, análisis que continuaron en la década de $1990 .{ }^{19}$ Las labores tomaron fuerza en el período 2006-2011, bajo la dirección del doctor Roberto Valcárcel Rojas, quien aplicó nuevos conceptos e ideas, y análisis multidisciplinar, para renovar el estudio de las evidencias y el contexto arqueológico. Los trabajos se dirigieron a valorar los procesos de interacción hispano-indígena en el sitio, a partir de los estudios precedentes.

Distintos sitios con evidencias de la interacción indohispana también se han localizado en Pueblo Viejo de Nuevitas, provincia Camagüey, ${ }^{20}$ y en Pueblo Viejo, de la provincia Sancti Spíritus. En este último, los investigadores aseguran haber hallado el asentamiento primario de la villa espirituana, fundada en $1514 .^{21}$

Las investigaciones mencionadas indican que aquellas cerámicas con formas europeas y técnicas nativas, así como otros artefactos manufacturados mediante la reutilización de fragmentos de cerámicas hispanas, son materiales que parecen evidenciar un intercambio cultural en épocas muy

16 Domínguez, 1984, 29-95; Valcárcel, 1997, 68.

17 García, 1938, 45-58.

18 García, 1938, 1939, 1940, 1942 y 1949; Rouse, 1942; Morales y Pérez, 1946; Miguel, 1949.

19 Valcárcel, 2012, 81.

20 Hernández et al., 2013.

21 Álvarez et al., 2012, 243-244. 
FIGURA 4

EJEMPLOS DE CERÁMICA DE TRANSCULTURACIÓN ELABORADAS POR EL MÉTODO DE ACORDELADO

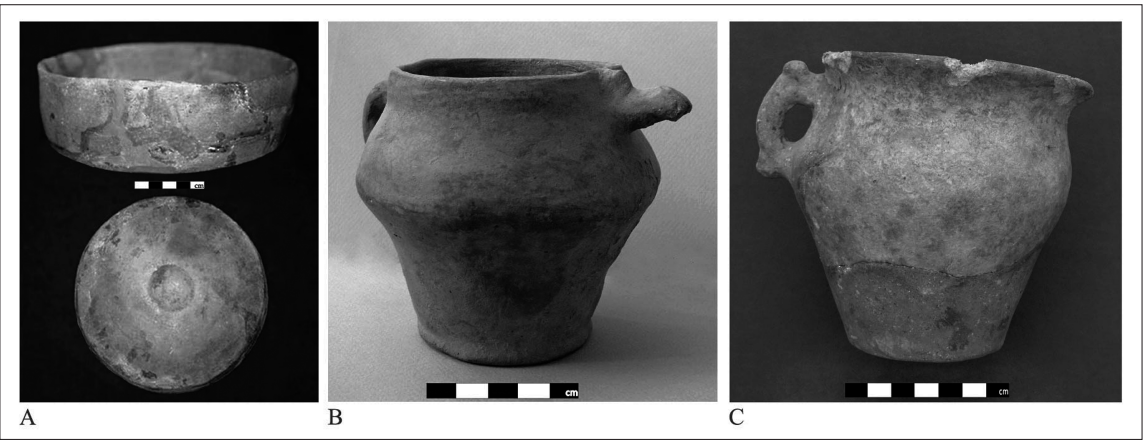

Las piezas reproducen formas hispanas de finales del siglo XV e inicios del XVI. A: Escudilla del sitio Las Bocas, provincia Sancti Spíritus. B: Jarra del sitio El Porvenir, provincia Holguín. C: Jarra del sitio El Yayal, provincia Holguín.

Fuente: Fotografías de Orlando Álvarez de la Paz (A) y Roberto Valcárcel Rojas (B y C).

tempranas de la conquista y colonización de Cuba. Podría argüirse, entonces, que los sitios que contengan exclusivamente este tipo de ítems, relacionados con un momento histórico concreto, lógico y necesario en la evolución de las relaciones sociales entre culturas diferentes, corresponden con la fase de situación de contacto, y no deben tomarse como arquetipos del proceso transcultural ni tipificarse como tal. Aun cuando el contacto cultural forma parte del proceso de transculturación, en estos artefactos se evidencia un incipiente canje y apropiación de elementos culturales y son notables sus diferencias con las halladas en contextos pertenecientes a la situación colonial.

\section{La Cerámica de Tradición Aborigen en los contextos habaneros}

Corresponde a la arqueóloga Lourdes Domínguez haber caracterizado y nombrado como Cerámica Transcultural al mismo tipo que hoy denominamos de Tradición Aborigen. Cantidades importantes de esta fueron 
halladas por el profesor Rodolfo Payarés y la referida especialista en las excavaciones de la Casa de la Obrapía o de Calvo de la Puerta, ${ }^{22}$ La Habana Vieja. Este inmueble fue erigido en la década de 1640, y fue objeto de investigaciones arqueológicas entre los años 1967 y 1970. Según Domínguez, la cerámica transcultural se halló en todas las excavaciones realizadas en el inmueble, ${ }^{23}$ asociada a mayólicas españolas, mexicanas y porcelana china de los siglos XVI y XVII, aunque se observan evidencias con rangos cronológicos entre los siglos XVII y principios del XVIII.

Entre los años 1968 y 1974, durante la restauración del otrora Palacio de los Capitanes Generales, ${ }^{24}$ actualmente Museo de la Ciudad de La Habana, el doctor Eusebio Leal y el arqueólogo Leandro Romero realizaron excavaciones arqueológicas y hallaron significativas cantidades del mismo tipo de alfarería. Se rescataron cuencos y ollas elaborados por la técnica manual del acordelado, sin decoración. Estas últimas fueron sometidas a análisis químicos, en los que se hallaron adheridos en las paredes interiores restos de alimentos que contenían albúminas y ácidos grasos, lo cual, junto a la gran concentración de hollín en las paredes exteriores, constituyeron elementos definitorios para afirmar que estas fueron utilizadas en el proceso de cocción de los alimentos. ${ }^{25}$

En el sitio arqueológico ubicado en la calle Mercaderes n. ${ }^{\circ} 15, \mathrm{La}$ Habana Vieja, Romero realizó excavaciones de salvamento en 1976. Allí exhumó un importante grupo de fragmentos de mayólicas españolas del siglo XVI, y «materiales de transculturación», los cuales consideró tentativamente como «el conjunto aislado más antiguo que conocemos para La Habana Vieja o colonial». ${ }^{26}$

Entre los años 2004 y 2005, durante la restauración ejecutada en el Castillo de la Real Fuerza, La Habana Vieja, se realizaron excavaciones arqueológicas en la entrada principal, que permitieron localizar un retrete o letrina (Figura 5). El contexto identificado estaba integrado por numerosos tiestos de Cerámica de Tradición Aborigen, asociados con mayólicas españolas y mexicanas, monedas macuquinas de plata, restos óseos de dieta y cientos de cañas y pipas inglesas de arcilla blanca de la primera y segunda mitad del siglo XVIII.

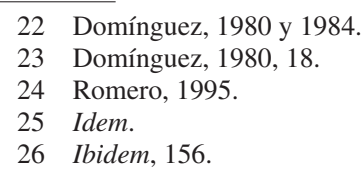


FIGURA 5

CASTILLO DE LA REAL FUERZA (1558-1579)

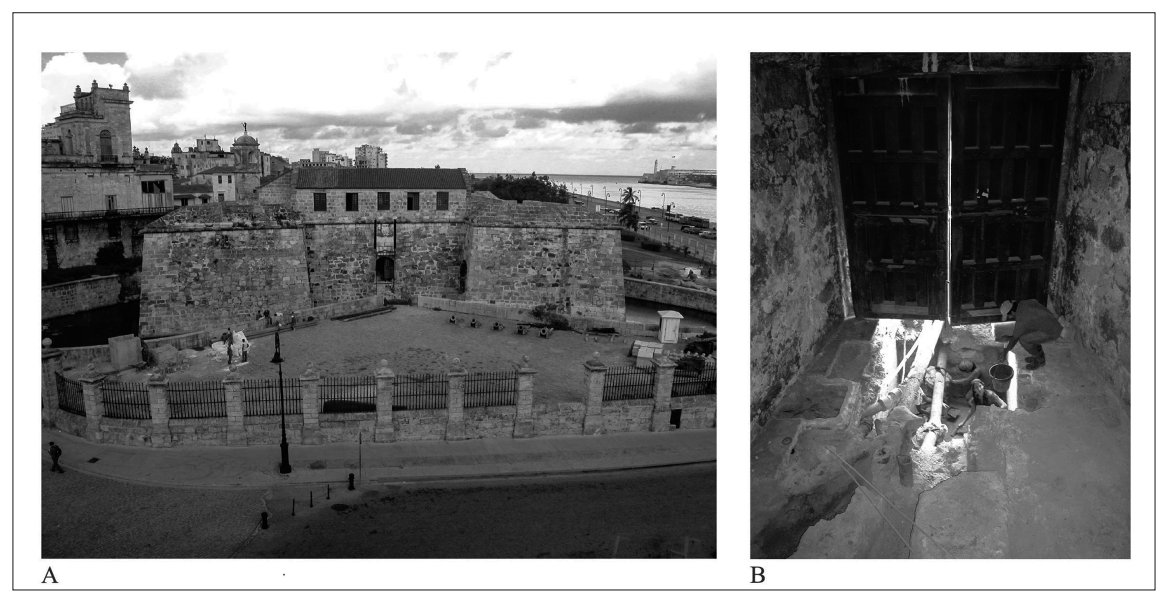

A: Aspecto de la fortificación durante su restauración. B: Excavación arqueológica de la letrina bajo la puerta principal del castillo (2005).

Fuente: Fotografías de Roger Arrazcaeta Delgado.

El Convento San Francisco de Asís, en La Habana Vieja, excepcional edificación reconstruida entre los años 1719-1738, constituye un sólido conjunto arquitectónico en el que el Gabinete de Arqueología ha realizado tres campañas de excavaciones arqueológicas. Las pechinas del coro alto de la Basílica Menor se hallaban rellenadas por un gran conjunto de ceramios (Figura 6b), colocados durante el proceso de construcción de dicho coro, posiblemente entre los años 1730-1738. Muchos de los recipientes estaban completos o fragmentados in situ, y conformaban una colección integrada por hormas de azúcar, jarras de aceite de estilo medio, jofainas, tinajas, bacines, platos, fuentes de mayólica y jarritas, entre otras formas. Lo más relevante de las evidencias fueron las cazuelas u ollas de Cerámica de Tradición Aborigen (Figura 6b), algunas de las cuales habían sido usadas en la cocina, pero otras poseían rajaduras originadas durante el proceso de cocción y nunca fueron utilizadas. Este importante hallazgo constituye una prueba irrefutable de que la producción y consumo de este tipo cerámico estaba plenamente vigente en el primer tercio del siglo XVIII. 
FIGURA 6

BASÍLICA MENOR DE SAN FRANCISCO DE ASÍS Y CERAMIOS HALLADOS EN SU CORO ALTO.

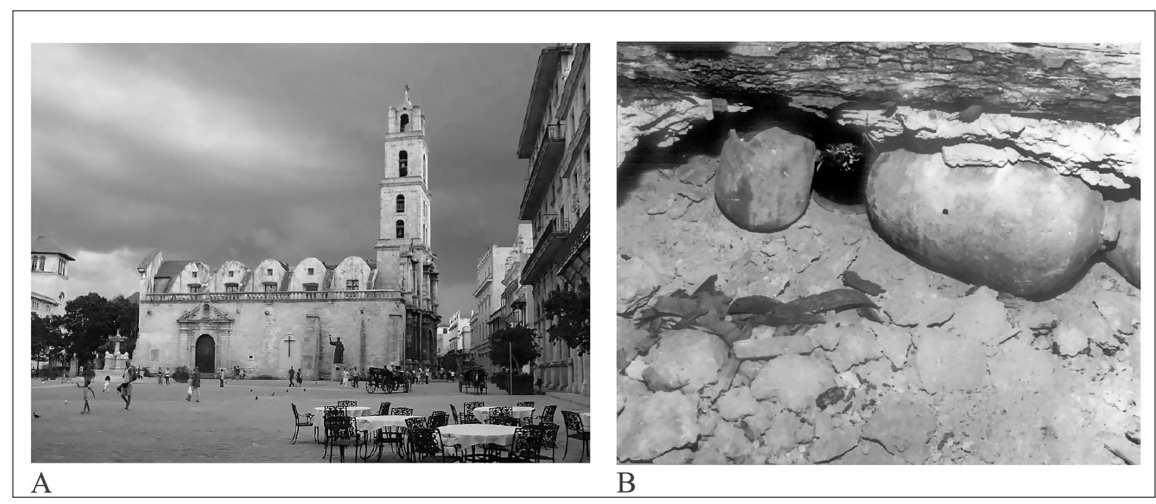

Obsérvese, entre los ceramios, hacia la izquierda, olla de Cerámica de Tradición Aborigen.

Fuente: Fotografías de Roger Arrazcaeta Delgado.

El convento de Santa Clara de Asís, también ubicado en La Habana Vieja, es la edificación conventual en pie más antigua de Cuba; su primer claustro e iglesia fue construido entre los años 1638 y 1644. En todos los locales y patios intervenidos se han hallado abundantes tiestos de Cerámica de Tradición Aborigen, compartiendo contexto con miles de restos de mayólicas mexicanas y europeas, cerámica burda torneada, porcelana china, fragmentos óseos de dieta, vidrio y restos metálicos, en una estratificación arqueológica que corresponde con los finales del siglo XVII.

A partir del año 2005, se realizaron investigaciones arqueológicas en el inmueble n. ${ }^{\circ}$ 162, ubicado en la calle Mercaderes en La Habana Vieja (conocido como Almacén de la Ferretería Isasi). Dos grandes cortes o huecos de canteras fueron identificados, ejecutados con el fin de extraer materiales de construcción en el siglo XVI. Estos se encontraban rellenados con una formidable colección de evidencias de la referida centuria. Los tiestos de Cerámica de Tradición Aborigen fueron abundantes y diversos, entre estos se distinguen una singular olla de forma navicular con asas de cornamusa (Figura 7b), fragmentos de burenes y varios tiestos de bordes de ollas con decoraciones incisas, entre otros. 


\section{FIGURA 7}

\section{EXCAVACIONES Y CERAMIOS HALLADOS EN LA HABANA}

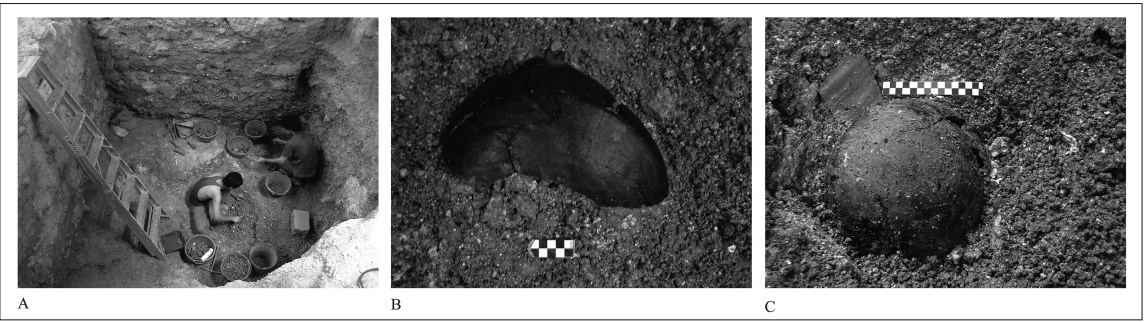

A: Hueco de cantera del siglo XVI. B: Olla navicular con asas de cornamusa. Sitio Almacén de la Ferretería Isasi, La Habana Vieja. C: Relación contextual in situ de la Cerámica de Tradición Aborigen con materiales de diversa procedencia y tipología. Muralla Marina de La Habana.

Fuente: Fotografías de Roger Arrazcaeta Delgado y Lisette Roura Álvarez.

\section{FigURA 8}

\section{EXCAVACIONES ARQUEOLÓGICAS DE LA MURALLA MARINA DE LA HABANA (2006)}

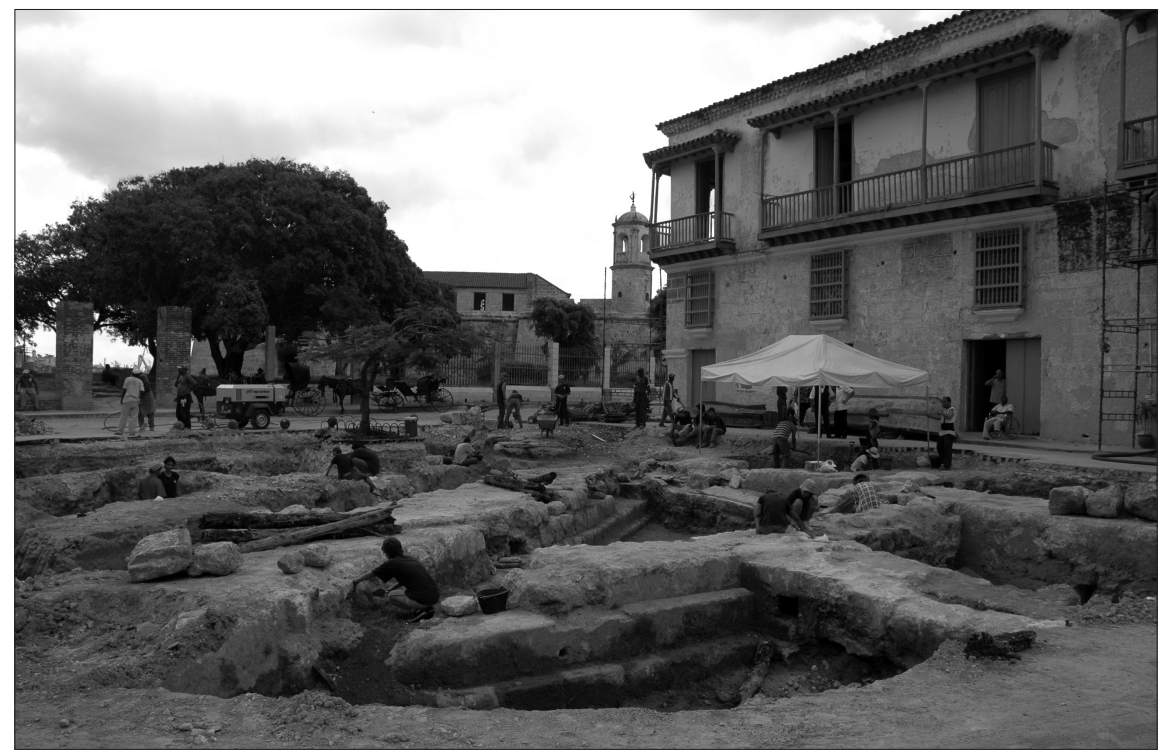

Fuente: Fotografía de Roger Arrazcaeta Delgado. 
La llamada casa de Pablo Pedroso es una de las mansiones coloniales más antiguas e importantes de La Habana Vieja, edificada entre los años 1624 y 1631. El contexto arqueológico descubierto resultó complejo, e incluyó los restos de una grada de construcción naval de finales del siglo XVI o principios del XVII, letrinas y pavimentos del inmueble, un pozo, rellenos de nivelación, canteras, cimientos de construcciones precedentes y un relevante muladar de la ciudad anterior a la construcción de la casa. El muladar o basurero urbano aportó gran cantidad de tiestos cerámicos y restos óseos de dieta. Entre las evidencias exhumadas, destacaron las Cerámicas de Tradición Aborigen, en este caso de finales del siglo XVI y primer cuarto del XVII.

Otro importante sitio intervenido fue la Muralla Marina de La Habana, terminada de construir hacia el año $1740 .{ }^{27}$ Los múltiples rellenos antrópicos resultaron muy ricos en cultura material de los siglos XVIII y XIX; fueron exhumados cientos de fragmentos de cazuelas de alfarería, elaborados por la técnica de rollos o cordeles, que clasificamos como de Tradición Aborigen.

Recientemente (2019), la consecución de las investigaciones arqueológicas en Guanabacoa ha permitido intervenir contextos muy significativos, vinculados con la población india que allí residió. Los contextos del siglo XVIII develaron gran cantidad de fragmentos de Cerámica de Tradición Aborigen, incluyendo varios fondos de burenes y un borde de cazuela inciso, el ejemplar decorado más tardío hallado en el territorio habanero (Figura 9). Dichas evidencias se relacionaban espacialmente con materiales europeos, asiáticos y americanos, entre los que destacaron artefactos vinculados con la presencia de individuos pertenecientes a comunidades autóctonas floridanas.

FIGURA 9

BORDE DE CERÁMICA DE TRADICIÓN ABORIGEN INCISO HALLADO EN GUANABACOA

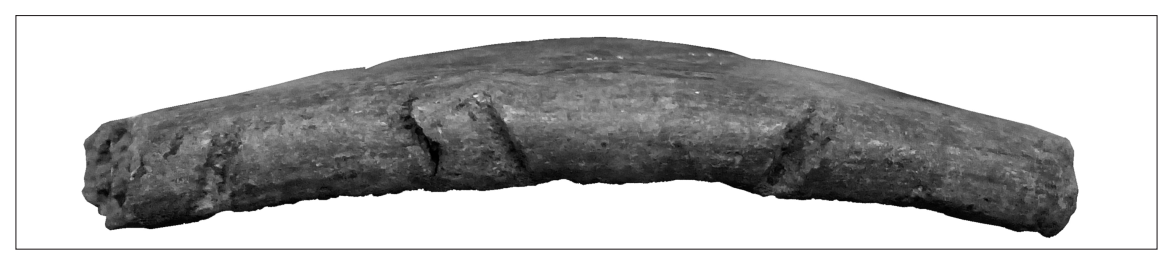

Fuente. Fotografía de Lisette Roura Álvarez.

27 Weiss, 1996, 140. 


\section{Materiales, métodos y tipología}

Para esta investigación fueron analizados artefactos procedentes de treinta y tres sitios arqueológicos ubicados en La Habana Vieja y Guanabacoa, intervenidos entre los años 1967 y 2019. Para obtener una visión integral de la muestra seleccionada, se realizó el análisis de los contextos y del material asociado, además de la compilación de información histórica y cartográfica de los sitos en estudio. La descripción cerámica fue ejecutada mediante microfotografías de las pastas con un microscopio digital Ecoline D-El 1, con aumentos de 10x hasta 40x. El examen de composición de las pastas lo realizó el físico nuclear Dr. Román Padilla Álvarez, del Centro

\section{FIGURA 10}

\section{PROBABLES ÁREAS DE ABASTO DE LAS ARCILLAS EMPLEADAS EN LA FABRICACIÓN DE LA CERÁMICA DE TRADICIÓN ABORIGEN}

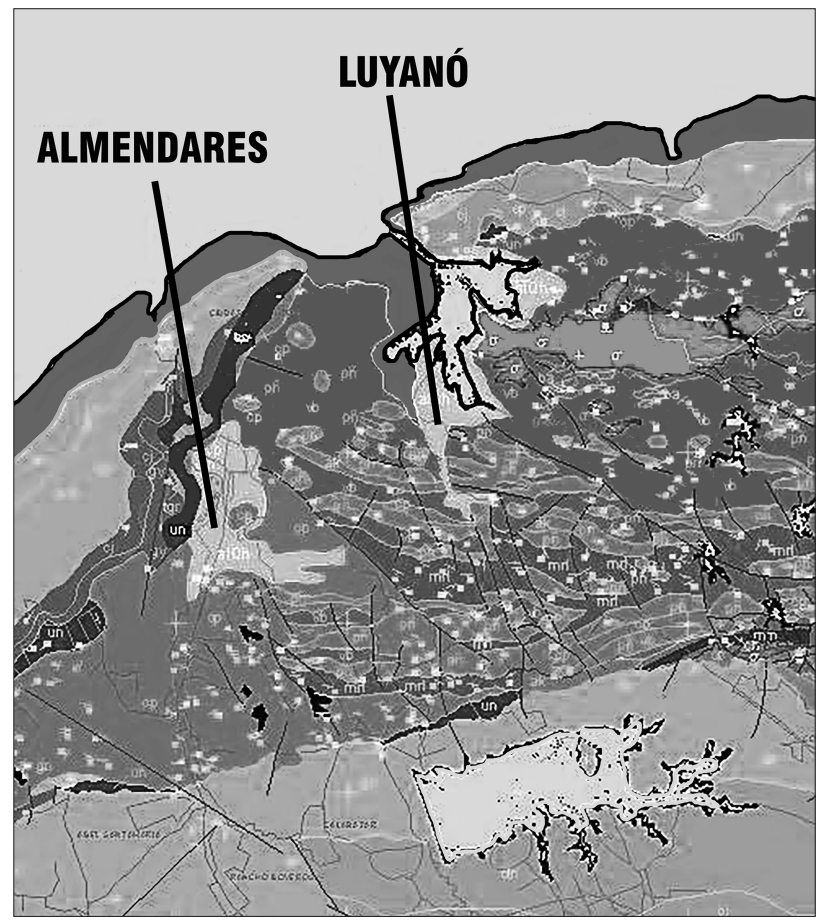

Fuente: Padilla, Arrazcaeta y Godo, 2003. 
de Estudios Aplicados al Desarrollo Nuclear (CEADEN) de Cuba. Este se llevó a cabo mediante la técnica de Análisis de Activación Neutrónica Instrumental (AANI). Otro grupo de muestras fueron analizadas en el Laboratorio Central de Minerales José Issac del Corral (LACEMI), a las cuales se les aplicó Petrografía, Análisis Térmico Diferencial (ATD) y Difracción por Rayos $\mathrm{X}$.

Los resultados de tales estudios amplían el espectro de posibilidades en cuanto a las fuentes de materia prima utilizadas para la confección de la Cerámica de Tradición Aborigen. Los estudios nucleares identificaron tres áreas fundamentales en las que se pudieron obtener las arcillas: las riberas del río Almendares (al oeste de la Bahía de La Habana) y los arroyos Luyanó y Martín Pérez (sureste de la Bahía de La Habana) (Figura 10). ${ }^{28}$ Sugieren además dos fuentes de aporte de arcillas en épocas diferentes, aunque pueden haber existido otras aun no estudiadas: los tiestos del siglo XVI pudieron ser elaborados con arcillas de las márgenes del río Almendares, mientras que los del siglo XVIII fueron modelados con arcillas de los ríos Luyanó y Martín Pérez, ambos ubicados en parte del antiguo territorio de los indios de Guanabacoa. El resto de los análisis concluyeron en la utilización de afloramientos de arcillas ubicados en Guanabacoa, en tierras que otrora pertenecieron a los indios naturales (Figura 11). ${ }^{29}$

\section{FIGURA 11}

\section{AFLORAMIENTOS OFIOLÍTICOS EN EL ANTIGUO TERRITORIO DE GUANABACOA}

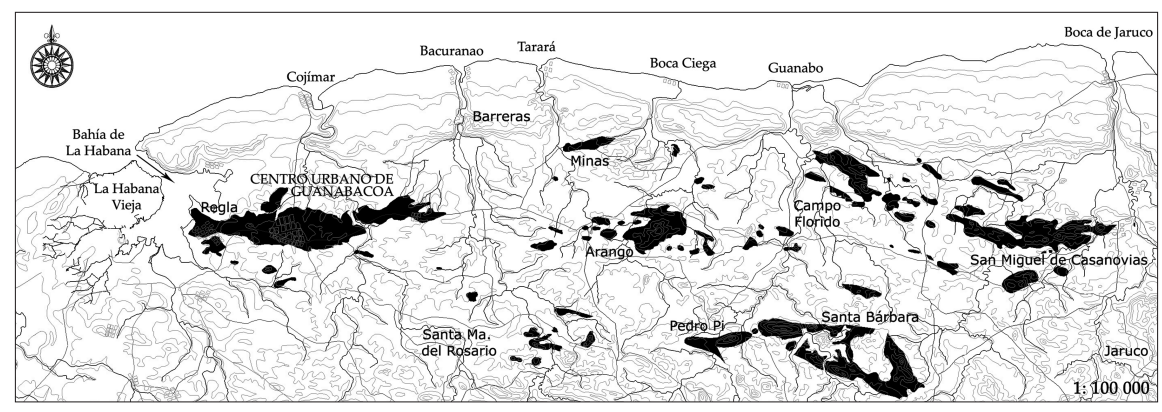

Fuente: Infografía realizada por Lisette Roura Álvarez, sobre el «Mapa Geológico de Cuba» (1999-2003). Extraída de Roura, Arrazcaeta y Hernández, 2017.

28 Padilla, Arrazcaeta y Godo, 2003.

29 Torres, 1998. 
Los análisis practicados permitieron conformar el ceramógrafo de la tipología en estudio:

\section{Pastas}

- Método de manufactura: A mano, método de acordelado. Presencia de huellas de espatulado y alisado; muestra cierta calidad en el acabado.

- Composición de las arcillas: Se emplearon arcillas bentonitas del tipo de montmorillonita, contentivas de hierro.

- Contenido de $\mathrm{CaCO}_{2}$ : Oscila entre un 7 y un $21 \%$.

- Nivel de selección de las arcillas: Es variable, hallándose ejemplares con granos de fracción fina hasta gruesa de más de $2 \mathrm{~mm}$.

- Grado de porosidad: Fluctúa entre un 4 y un $7 \%$, mejorándose la impermeabilidad de las piezas por el trabajo de alisado, que puede ser observado en la superficie externa.

- Cocción: Los análisis petrográficos dictaminaron la ausencia de bandas, denotando una baja temperatura de cocción; este resultado apunta hacia la utilización de hornos abiertos. En los ejemplares donde puede observarse el centro de la pasta se identifica una atmósfera oxidante, proceso coincidente con el uso de esta técnica de cochura.

- Color: La mayoría de los tiestos analizados fueron utilizados en la cocción de alimentos, por lo tanto, la pasta presenta un tono negruzco, con frecuente presencia de hollín.

- Fractura: Irregular, se desprenden partículas en los bordes de la ruptura.

- Dureza: Desde 2 hasta 3 en la escala de dureza de Mohs.

\section{Tratamiento de la superficie}

- Color: Negruzco, producido por la exposición constante al fuego.

- Tratamiento: El tratamiento de la superficie de los ceramios muestra el alisado regular y un frecuente espatulado que le imprime a algunos ejemplares cierto pulimento o lustre en la cara exterior. La cara interior es más variable, pues se encuentra desde similar tratamiento, hasta un alisado irregular que permite ver las uniones entre rolletes.

- Desgrasante: Los antiplásticos encontrados fueron la arena, el cuarzo, óxidos de hierro y otros materiales, así como rocas por identificar, con partículas de hasta $2 \mathrm{~mm}$. Según la escala para la clasificación de Hargrave y Smith, este desgrasante se puede catalogar como muy burdo, pues sobrepasa los $0,8 \mathrm{~mm} \cdot{ }^{30}$

30 Cruxent, 1980, 55. 


\section{Formas}

- Bordes: Los tipos de bordes identificados fueron los invertidos, evertidos y en menor número los acintados. Los labios o topes de los bordes en todos los casos son redondeados.

- Espesor de las paredes: El espesor de las paredes varía entre 3 y $23 \mathrm{~mm}$. Los ejemplares del siglo XVI tienen un predominio de grosores menores a $10 \mathrm{~mm}$, aumentando paulatinamente en el siglo XVII con predominio de valores entre 7 y más de $10 \mathrm{~mm}$. El grosor de las paredes de ceramios del siglo XVIII es mayor, con predominio de valores que oscilan entre $9 \mathrm{~mm}$ y más de $10 \mathrm{~mm}$.

- Base: Las bases de los ceramios estudiados son convexas y esporádicamente aparece alguna plana; en el caso de los burenes las bases son planas.

- Principales formas: Cuencos, ollas (grandes y medianas), potes y burenes.

\section{Decoración}

- Motivos y técnicas: Se han reportado muy pocos ejemplares con decoración; los identificados son muy sencillos y de tipo inciso sobre el labio, generalmente en el coronamiento de estos, siempre en la pasta húmeda. Varios ejemplares presentan una misma decoración, consistente en pequeñas líneas paralelas entre sí, y otros muestran bordes evertidos con filete u orla inciso. Todos los ejemplos corresponden a los siglos XVI y XVII.

- Asas: Las asas no son frecuentes. Se han podido identificar asas de lazo, de barbotina, de tetón y cornamusa. ${ }^{31}$

- Posición cronológica: Este tipo cerámico ha sido recuperado ampliamente en contextos correspondientes con los siglos XVI, XVII, XVIII y XIX temprano, aunque en este último con una presencia mínima.

El material cerámico se clasificó tomando en cuenta los criterios de tipo-variedad, los conceptos metodológicos de José M. Guarch (1978) en lo concerniente a la diversidad de formas y tamaños cerámicos, y José M. Cruxent (1980) en la descripción y los conceptos de análisis del ceramógrafo. Así mismo, se tomaron en cuenta los estudios cerámicos efectuados por Kathleen Deagan (1987) para la contextualización del material de estudio, y para evitar posibles confusiones con otros tipos cerámicos que aparecen en los sitios históricos hispanoamericanos.

31 Roura, Arrazcaeta y Hernández, 2017, 86-88. 


\section{FIGURA 12}

OLLAS Y POTE DE CERÁMICA DE TRADICIÓN ABORIGEN HALLADAS EN LA HABANA VIEJA

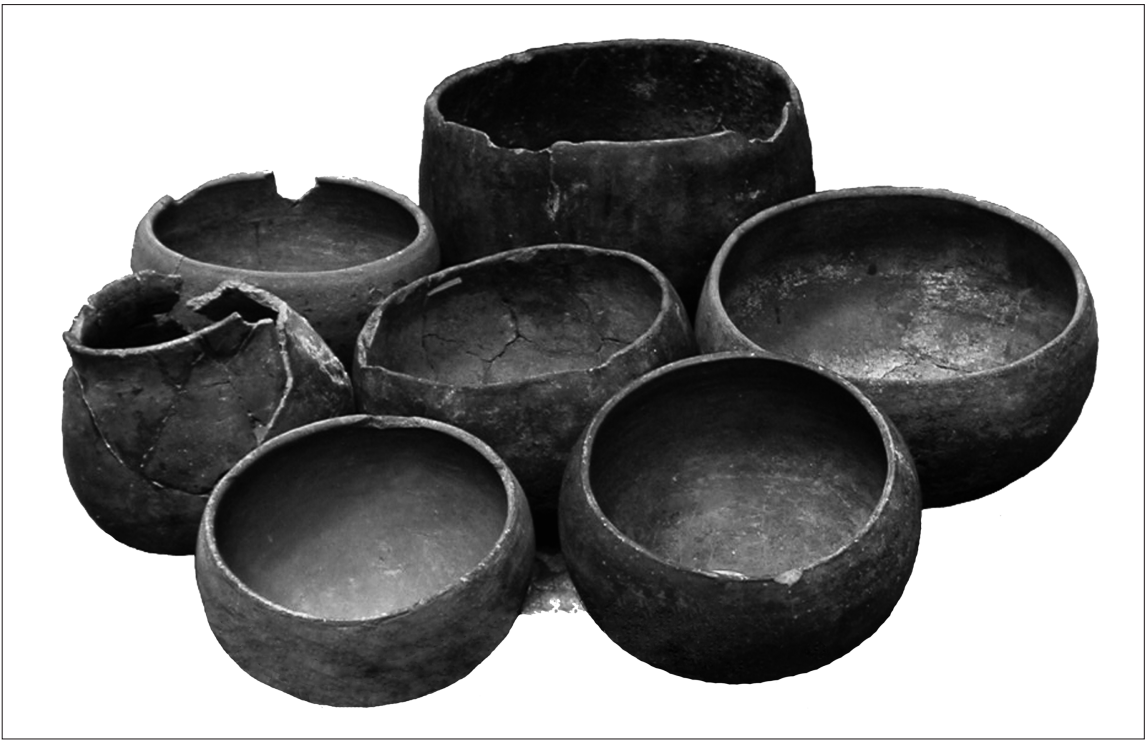

Fuente: Fotografía de Lisette Roura Álvarez.

\section{Tradición y transculturación}

Las características observadas en los ceramios manifiestan la gradual supresión de decoraciones y tipologías de asas, además de la simplificación de las incisiones. Se siguieron utilizando hornos abiertos y cerrados muy rústicos en algunos casos para lograr agilizar las producciones alfareras. Tampoco se implementó el uso del torno como adelanto tecnológico y, escasamente y por un período corto, se incorporaron la reproducción de formas y decoraciones europeas. Por tanto, esta tipología cerámica no debe catalogarse como Cerámica de Transculturación, pues, aunque las simplificaciones de formas y ausencia de particularidades típicas de las cerámicas producidas por las comunidades autóctonas también aludan al proceso transcultural, sus atributos formales no indican que sea realmente un producto nuevo del «[...] proceso en el cual ambas partes de la ecuación 
resultan modificadas. Un proceso en el cual emerge una nueva realidad, compuesta y compleja; una realidad que no es una aglomeración mecánica de caracteres, ni siquiera un mosaico, sino un fenómeno nuevo, original e independiente». ${ }^{32}$

Es innegable el transitar de los indios habaneros por el proceso de transculturación, sin embargo, al menos en lo que respecta a la alfarería, la transculturación parece haber condicionado un comportamiento singular. Es posible que, debido a que las formas de las vasijas elaboradas por los naturales para la venta y consumo de la población - específicamente las ollas, los potes y los cuencos- concordaban con formas hispanas similares, también dedicadas a funciones culinarias, no fuera necesario entonces fabricar imitaciones o aproximaciones a la cerámica importada. Su fabricación supone la presencia de un «[...] legado que se transmite de generación en generación, por obra de un sujeto transmisor a un sujeto receptor. Lo que se transmite, en su esencia, es un acervo permanente de verdades vitales que asumen diversas y renovadas formas históricas». ${ }^{33}$ Esta tradicionalidad connota además un conjunto heredado de rasgos identitarios, elementos del legado sociocultural que durante largo tiempo se mantienen en la sociedad o en distintos grupos sociales. Refiere también el desarrollo continuado de una misma actividad en un territorio determinado. Fijar atención en estos aspectos posibilita comprender los procesos culturales vinculados a las tradiciones alfareras de la descendencia aborigen habanera y su permanencia hasta la primera mitad del siglo XIX.

Otro elemento que merece ser abordado en este análisis es la importancia adquirida por el Puerto de La Habana debido al comercio trasatlántico e intercolonial durante los siglos XVI, XVII y XVIII, dada su posición geográfica estratégica en el tráfico con España y las colonias americanas. El resto de los asentamientos hispanos de la Isla, al encontrarse alejados de las principales rutas comerciales y distantes de La Habana, fueron menos favorecidos en cuanto a la entrada de mercaderías. La población europea se vio forzada a interactuar más activamente con los naturales, lo cual determinó un mayor empleo de artefactos indígenas, y a la vez una influencia más directa sobre los ceramios producidos por estos. Es probable que las vasijas imitaran patrones hispanos con el objetivo de suplir la carencia de determinadas formas cerámicas, que poseían usos muy específicos dentro de las costumbres y tradiciones españolas. Pero también es posible que los

32 Ortiz, 1991, XXXIII.

33 Anales del Primer Congreso Nacional de la Tradición, 1968, 195. 
indios que habitaban estos territorios mantuvieran la tradición alfarera, y confeccionaran ceramios similares a los hallados en La Habana. Por ello, las características perceptibles en los artefactos habaneros de los siglos XVI y XVII, como las decoraciones incisas y la presencia de asas, pueden ser observadas en lotes de ítems cronológicamente pertenecientes al siglo XVIII en Holguín y Camagüey.

FigURA 13

DISTRIBUCIÓN ESPACIAL DE LA CERÁMICA DE TRADICIÓN ABORIGEN (ACP)

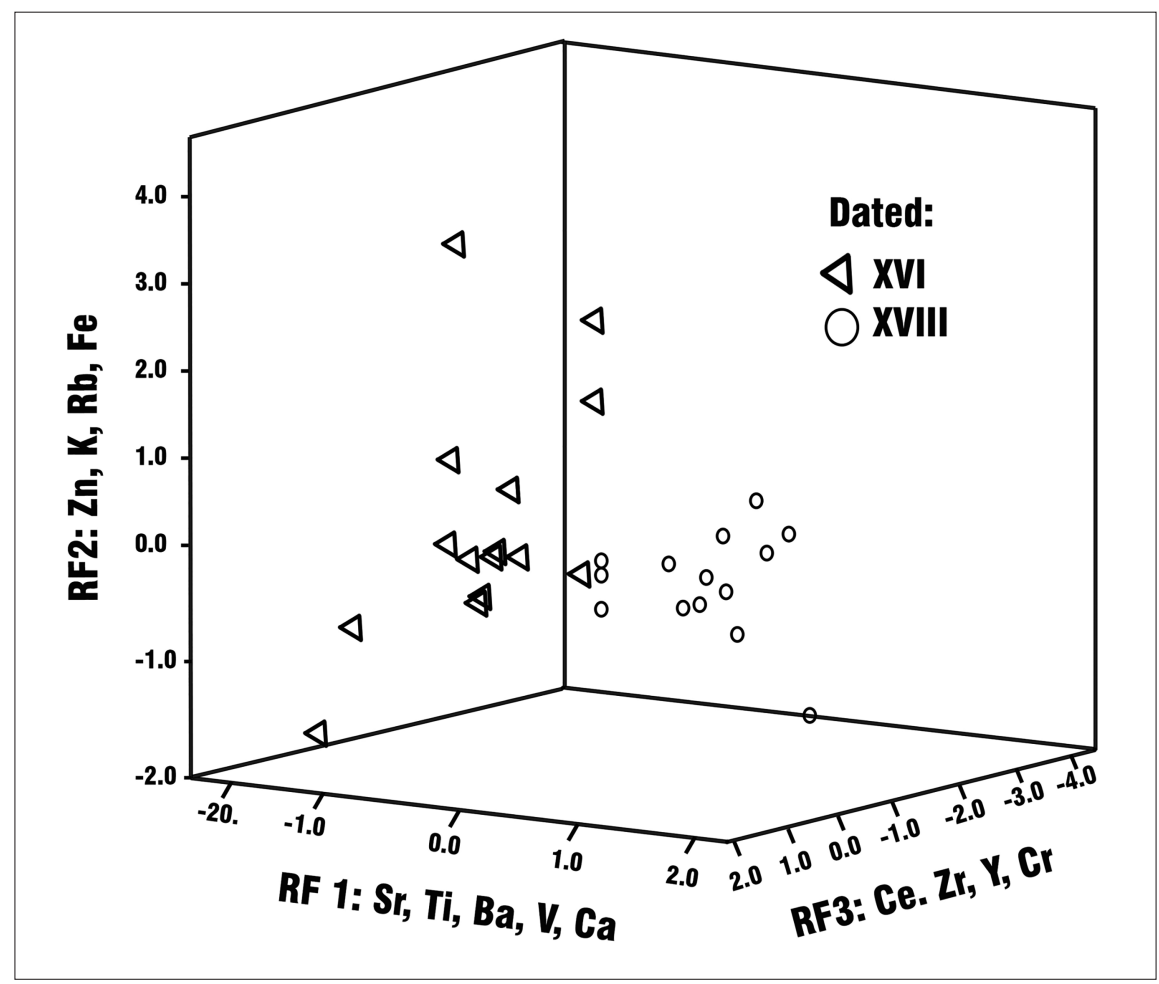

Los triángulos identifican los fragmentos de la excavación n. 3 del Almacén de la Ferretería Isasi, contexto de la segunda mitad del siglo XVI; los círculos, a los procedentes de una letrina del Museo Castillo de la Real Fuerza, contexto del siglo XVIII.

Fuente: Infografía realizada por Román Padilla y Roger Arrazcaeta; extraída de Padilla, Arrazcaeta y Godo, 2003. 
Cada territorio posee particularidades contextuales que difieren de otras regiones y pueden estar reflejadas en la cultura material generada. En cada urbe deben evidenciarse grados de interacción cultural a ritmos y escalas diferentes. La Habana constituyó un escenario de vastos procesos sociohistóricos, lo que incidió en la aceleración de la transculturación, proceso ininterrumpido de transición de una cultura a otra, dinámico, dialéctico e indetenible. Las manifestaciones transculturales a partir del contacto y la situación colonial se evidencian a largo plazo, cuando se ha transitado por otros procesos, que intrínsecos dentro del general transcultural, lo caracterizan. La fusión no abarca solo las artes: es ubicua. «En lo importante y ostensible se impuso el modelo de Europa; en lo doméstico y lo cotidiano se conservaron muchas tradiciones indígenas». ${ }^{34}$

Las evidencias artefactuales de transculturación objetivamente se han considerado en sus aspectos formales como materiales que manifiestan la proporción del grado de intercambio cultural, y, por lo tanto, de transculturación como proceso gradual con perfiles estaduales más o menos avanzados, según la materia prima, las formas y los componentes decorativos. Una posición reduccionista puede argumentar con facilidad la transculturación como solución inmediata a la diversidad y complejidad de los cambios culturales producto de la interacción social. No se toma en cuenta el hecho de que cada individuo o grupo de individuos pudo haber asimilado/enfrentado el proceso «civilizatorio» de diferentes maneras, con matices, desde la identidad y la diferencia, de oposición y contradicción. De lo anterior parte el argumento de una probable participación diferencial de, al menos, una parte de los naturales habaneros.

Cada producto de estos procesos es una manifestación diversa, según las condiciones materiales y la situación histórica particular, con diferentes niveles de objetivación. Desde la representación de la propia categoría de transculturación, y asumiendo que la imposición de costumbres e ideologías no debió haber sido bienvenida, sino más bien resistida y rechazada, se puede argumentar que el resultado liminal conllevó al arraigo de los aborígenes y sus descendientes a las maneras de hacer y producir que les eran habituales. La posición de resistencia de la clase dominada resultó en el arraigo a patrones identitarios de su propia cultura, como recurso de refugio y supervivencia, como defensa ante los procesos de deculturación y los mecanismos de hegemonía de las clases dominantes. En La Habana, estos se

34 García, 1988, 10. 
concretizaron en la Cerámica de Tradición Aborigen como una de las múltiples respuestas de la descendencia indígena ante la dominación española.

En consecuencia, se asume que para ciertos grupos sometidos se hizo mucho más lento el proceso de apropiación de los nuevos elementos. Los análisis realizados hasta el momento, permeados de un enfoque dirigido al artefacto como evidencia directa del pasado, generalmente simplifican la complejidad del proceso de transculturación. Esta perspectiva, fundamentada en la metodología tradicional de investigación de la arqueología en Cuba, toma los hechos sociales como objetivaciones al margen de los sujetos, sus intersubjetividades y prácticas cotidianas, aunque se argumente y se haga explícito que no se puede perder de vista a los seres humanos que «están detrás de cada artefacto».

Los referentes históricos y arqueológicos hallados, a pesar de la perdurabilidad temporal de elementos culturales autóctonos, no permiten afirmar que la descendencia aborigen se autoidentificara como grupo étnico. Es probable que, en este caso, varios elementos no constituyeran unidad portadora de cultura, aun cuando fueron reconocidos por los europeos, criollos blancos, mestizos, africanos y negros libertos, como pertenecientes a una categoría distinguible. Es posible que, hasta la segunda mitad del siglo XVI y primera del XVII, teniendo en cuenta el registro arqueológico, la descendencia indígena se autoperpetuara mediante medios biológicos, compartiera rasgos identitarios, e interactuaran más intensamente entre ellos. La autodefinición como indios o naturales reflejada en los documentos, probablemente tuviera un propósito interaccional para ellos y diferencial para la sociedad donde se insertaban. La información documental y arqueológica confirma que, con el paso del tiempo, las diferencias culturales fueron desapareciendo, el proceso de transculturación condicionó la transformación de la descendencia indígena, y, hacia la primera mitad del siglo XIX, estos individuos ya no eran reconocidos como indios o naturales, sino como pobladores que formaban parte de los sectores más humildes de la sociedad colonial habanera.

\section{Consideraciones finales}

La cronología definida para la Cerámica de Tradición Aborigen, ampliamente representada en los contextos históricos de La Habana Vieja y Guanabacoa de los siglos XVI, XVII y XVIII, demuestra que su fabricación, demanda, distribución y consumo fueron sumamente exitosas. Las 
tres probables fuentes de aporte de arcilla, una ubicada al oeste de la Bahía de La Habana (río Almendares), otra al sureste de esta (ríos Luyanó y Martín Pérez), y la tercera en territorio guanabacoense, evidencian la probable existencia de tres centros de producción alfarera. No obstante, también es posible que en alguna parcela de tierra en posesión de indios avecindados ubicada en los parajes con fuentes de arcilla, existiera algún alfar primitivo donde se confeccionara y cociera el tipo de cerámica referida.

Los cambios que se observan en el aumento del tamaño y grosor de los ceramios, pérdida de la decoración y ausencia de asas o soportes, son fuertemente apreciables en los especímenes de fines del siglo XVII y sobre todo en los del XVIII. En los ejemplares del XVI y XVII, esas transformaciones son más lentas y menores. El dinámico cambio en el siglo XVIII podría estar relacionado con una disminución del componente poblacional y rasgos culturales indígenas, y una fuerte presencia del africano y su descendencia en el proceso de fabricación de los ceramios.

El estudio del conjunto cerámico resultó en la retipificación de ollas, potes, burenes y cuencos acordelados, proponiendo el tipo Cerámica de Tradición Aborigen, quedando obsoletos los términos Cerámica Transcultural o Cerámica del Período de Contacto y Transculturación, al menos para contextos donde se evidencie la situación colonial, pues son realmente las tradiciones indígenas aruacas las que perviven y predominan en esta producción alfarera. El análisis de los contextos arqueológicos en La Habana Vieja sustenta la convivencia entre europeos e indios en el área de mayor desarrollo urbanístico de la ciudad, independientemente de la forzosa concentración de estos últimos en Guanabacoa.

Mediante el análisis de los procesos sociohistóricos se puede argüir que, tanto en La Habana como en Guanabacoa, estos presentaron particularidades que conllevaron a situaciones de superordinación-subordinación, donde la cultura española mantuvo una posición dominante debido a su superioridad tecnológica y militar, al empleo de la fuerza y a la posesión de extensos territorios. Sin embargo, rasgos culturales autóctonos persistieron y se transocializaron como componentes de un grupo cultural oprimido, sometido y condenado a expresiones de marginalidad. La Cerámica de Tradición Aborigen es el reflejo directo del comportamiento de los individuos que componían dicho grupo cultural, ya que a lo largo de la historia los sujetos han manipulado la cultura material, siendo los significados, creencias e ideas, los que se interponen entre la gente y las cosas, interpretados gracias a sus relaciones contextuales. 
En los próximos años será necesario ampliar los estudios arqueológicos en el municipio Guanabacoa, así como continuar realizando análisis arqueométricos y comparativos de las pastas cerámicas, para alcanzar un mayor nivel cognoscitivo sobre esta tipología cerámica y sus hacedores.

\section{Agradecimientos}

Expresamos nuestro sincero agradecimiento a los arqueólogos Iosvany Hernández y Juan G. Martín, por su gentil invitación a participar en el I Encuentro Científico ArtEmpire. También agradecemos a Iosvany la información brindada sobre el sitio Pueblo Viejo, Nuevitas, Camagüey, Cuba. Gracias a los colegas Karen M. Lugo, por la revisión y sugerencias a este trabajo, a Marcos A. Acosta y Adrián Labrada, por su apoyo con el tratamiento digital de algunas imágenes. Asimismo, a Osvaldo Jiménez por su colaboración con el material arqueológico. A Sonia Menéndez, Rosalía Oliva y Alejandro Nolasco por su contribución con imágenes y fotografías.

Recibido, 13 de abril de 2020 Segunda versión, 28 de agosto de 2020 Aceptado, 4 de septiembre de 2020

\section{Referencias bibliográficas}

Álvarez de la Paz, Orlando et al., «En busca del origen de la villa de Sancti Spíritus», Gabinete de Arqueología, 9, La Habana, 2012, 243-244.

Anales del Primer Congreso Nacional de la Tradición, Buenos Aires, Secretaría de Estado de Cultura y Educación, 1968.

Cruxent, José M., Notas Ceramológicas, Caracas, Ediciones UNEFM, 1980.

Deagan, Kathleen A., Artifacts of the Spanish Colonies of Florida and the Caribbean 1500-1800, vol. 1, Washington D. C., Smithsonian Institution Press, 1987.

Domínguez González, Lourdes S., «La transculturación en Cuba (s. XVI-XVII)», Cuba Arqueológica, I, Santiago de Cuba, 1978, 33-50.

Domínguez González, Lourdes S., «Cerámica de transculturación en el sitio colonial Casa de la Obrapía», Cuba Arqueológica II, Santiago de Cuba, 1980, 17-26.

Domínguez González, Lourdes S., Arqueología colonial cubana: dos estudios, La Habana, Editorial de Ciencias Sociales, 1984. 


\section{R. ARRAZCAETA DELGADO, L. ROURA ÁLVAREZ Y R. T. ORTIZ LINSUAÍN}

García Arévalo, Manuel, Arqueología e Identidad Nacional, Santo Domingo, Museo del Hombre Dominicano y Fundación García Arévalo, 1988.

García Castañeda, José A., «Asiento Yayal», Revista de Arqueología, 1, La Habana, 1938, 44-58.

García Castañeda, José A., «Asiento Ochile», Revista de Arqueología, 3, La Habana, 1939, 47-56.

García Castañeda, José A., «Asiento Pesquero», Revista de Arqueología, 4, La Habana, 1940, 56-60.

García Castañeda, José A., «Barajagua», Revista de Arqueología, 7-8, La Habana, 1942, 38-41.

García Castañeda, José A., «La transculturación indo-española en Holguín», Revista de Arqueología y Etnología, 8-9, La Habana, 1949, 195-205.

Guarch Delmonte, José M., El Taíno de Cuba. Ensayo de Reconstrucción Etnohistórica, La Habana, Dirección de Publicaciones Academia de Ciencias de Cuba, 1978.

Hernández Mora, Iosvany et al., «Investigación arqueológica en Pueblo Viejo de Nuevitas: Resultados estratigráficos de la Campaña 2012», Visiones Pretéritas. Encuentro arqueológico II, Camagüey, 2013, 57-85.

Miguel Alonso, Orencio, «Descubrimiento y excavación de un montículo funeral en el potrero "El Porvenir"», Revista de Arqueología y Etnología, 8-9, La Habana, 1949, 175-194.

Morales Patiño, Oswaldo y Pérez de Acevedo, Roberto, «El período de transculturación indohispánico», Revista de Arqueología y Etnología, 1, La Habana, 1946, 5-36.

Ortiz Fernández, Fernando, Contrapunteo cubano del tabaco y el azúcar, La Habana, Editorial de Ciencias Sociales, 1991.

Padilla Álvarez, Román y Arrazcaeta Delgado, Roger, «Classification of Majolica Pottery from Colonial Havana based on NAA», Nuclear Analytical Techniques in Archaeological Investigations, Viena, International Atomic Energy Agency, 2003, 135-146.

Romero Estévanez, Leandro, «Sobre las evidencias arqueológicas de contacto y transculturación en el ámbito cubano», Revista Santiago, 44, Santiago de Cuba, 1981, 71-105.

Romero Estévanez, Leandro, La Habana arqueológica y otros ensayos, La Habana, Editorial Letras Cubanas, 1995.

Roura Álvarez, Lisette; Arrazcaeta Delgado, Roger y Hernández Oliva, Carlos A., «La Cerámica de Tradición Aborigen: ejemplos habaneros», Gabinete de Arqueología, 5, La Habana, 2006, 16-27.

Roura Álvarez, Lisette; Arrazcaeta Delgado, Roger y Hernández Oliva, Carlos A., Indios de La Habana: aproximación histórico-arqueológica, La Habana, Editorial de Ciencias Sociales, 2017. 
Rouse, Irving. B., Archaeology of the Maniabon Hills, Cuba, New Haven, Yale University Press, 1942.

Torres, Manuel, Resultado de los análisis de muestras de cerámica ordinaria, La Habana, Laboratorio Central de Minerales José Issac del Corral, 1998.

Valcárcel Rojas, Roberto, «Introducción a la arqueología del contacto indohispánico en la provincia de Holguín, Cuba», El Caribe Arqueológico, 2, Santiago de Cuba, 1997, 64-77.

Valcárcel Rojas, Roberto, «Interacción colonial en un pueblo de indios encomendados. El Chorro de Maíta, Cuba», tesis doctoral dirigida por la Dra. Corinne L. Hofman, Universidad de Leiden, Holanda, 2012.

Valcárcel Rojas, Roberto, «Cuba. Indios después de Colón», en Ulloa Hung, Jorge y Valcárcel Rojas, Roberto (comps.), Indígenas e Indios en el Caribe. Presencia, legado y estudio, Santo Domingo, Instituto Tecnológico de Santo Domingo, 2016, 7-47.

Weiss Sánchez, Joaquín, La arquitectura colonial cubana siglos XVI al XIX, La Habana, Instituto Cubano del Libro, 1996. 